Graduate Institute of International and Development Studies

International Economics Department

Working Paper Series

Working Paper No. HEIDWP08-2017

\title{
The Size of Fiscal Multipliers and the Stance of Monetary Policy in Developing Economies
}

\author{
Jair N. Ojeda-Joya \\ Banco de la Republica, Bogotà D.C. \\ Oscar E. Guzman \\ Office of the National Comptroller, Bogotà D.C.
}

Chemin Eugène-Rigot 2

P.O. Box 136

CH - 1211 Geneva 21

Switzerland

(C) The Authors. All rights reserved. Working Papers describe research in progress by the author(s) and are published to elicit comments and to further debate. No part of this paper may be reproduced without the permission of the authors. 


\title{
The Size of Fiscal Multipliers and the Stance of Monetary Policy in Developing Economies
}

\author{
Jair N. Ojeda-Joya \\ Oscar E. Guzman*
}

\begin{abstract}
In this paper we estimate the effect of government consumption shocks on GDP using a panel of 21 developing economies. Our goal is to better understand the reasons for the low fiscal multipliers found in the literature by performing estimations for alternative exchange rate regimes, business-cycle phases, and monetary policy stances. In addition, we perform counterfactual simulations to analyze the possible gains from fiscal-monetary policy coordination. The results imply that government consumption shocks are usually followed by monetary policy tightening in developing economies with flexible regimes. Our simulations show that this reaction partially explains the presence of low fiscal multipliers in these economies. On the other hand, we find that government consumption shocks have better multipliers in developing economies during fixed regimes, economic booms and monetary expansions. In particular, implementing fiscal programs during monetary expansions seems to improve significantly their economic stimulus.
\end{abstract}

Keywords: Fiscal Policy, Monetary Policy, Structural Vector Autoregression, Exchange Rate Regime, Panel VAR

JEL classifications: E62, E63, F32

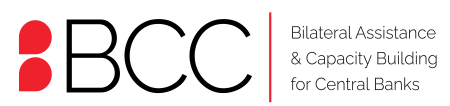

This research project was completed under the BCC programme, which is funded by the Swiss State Secretariat for Economic Affairs (SECO) and implemented by The Graduate Institute, Geneva.

\footnotetext{
- This version: February 2017. The findings, recommendations, interpretations and conclusions expressed in this paper are those of the authors and do not necessarily reflect the view of the Central Bank of Colombia or of the Office of the National Comptroller. We are grateful to Frank Westermann, Jan Kuckuck, Hernando Vargas and participants of the economics seminar at Osnabrück University for their generous comments and suggestions. We thank Gabriela Rubio for excellent research assistance.

^ Corresponding author: Senior Research economist, Banco de la Republica. Cr. 7 No. 14-78, Bogotá D.C., Colombia. E-mail: jojedajo@,banrep.gov.co

* Economic Advisor, Office of the National Comptroller, Bogotá D.C., Colombia. E-mail: oscar.guzman@,contraloria.gov.co
} 


\section{Introduction}

Having reliable estimations of fiscal multipliers is exceptionally important for central governments when evaluating new fiscal programs. However, there is a notable result for developing economies: their fiscal multipliers are very small, (Ilzetzki et al, 2013). On the other hand, it is known that fiscal multipliers which are derived from SVAR models include the predicted future path of policy instruments (Kuckuck and Westermann, 2014). This is because such estimations are typically performed with data which captures the historical reaction of monetary and tax policies to government consumption shocks. In this paper, we further explore the size of multipliers in developing economies by empirically evaluating the role of the implied monetary policy reactions in their determination.

We study a panel of quarterly data and 21 developing economies ${ }^{1}$. We use a Structural Vector Auto Regression (SVAR) (Blanchard and Perotti, 2002), within panel data estimation. In the case of fiscal policy, a key identification assumption is that changes in government consumption require at least a quarter to respond to innovations in the remaining macro variables, including GDP. In the case of monetary policy, we use the money stock as a control variable for money demand which reacts quickly to the macro environment. In contrast, policy interest rates take longer to react to macroeconomic news.

Opposite to the case of developed economies, our impulse-response functions imply that government consumption shocks are followed by monetary policy tightening in developing economies with flexible exchange rates. In addition, we perform counterfactual simulations to obtain fiscal multipliers which are free of the monetary policy reaction implied by the data. That is, we shut down the estimated policy rate reaction and allow all the remaining feedbacks of the system to operate. These simulations show that such tightening partially explains the presence of low fiscal multipliers in these developing economies. These results also imply that further fiscal-monetary policy coordination might be useful during the implementation of fiscal policy programs. In particular, we show that when the government consumption shock coincides with a monetary expansion, the multiplier increases significantly.

In related literature, several works have found that the size of fiscal multipliers is a function of specific macroeconomic features of the economies under study. Favero et al (2011) find heterogeneous results for the size of fiscal multipliers within a sample of developed economies even after controlling for macroeconomic features and using the narrative method to identify fiscal shocks. Auerbach and Gorodnichenko (2012) show that positive multipliers are mostly associated to recessions according to their estimations using OECD data and local projection methods. Kraay $(2012,2014)$ finds positive multipliers (around 0.5) in developing economies using credits from multilateral organizations as identification device. These multipliers are found to be significantly lower in open economies but still positive. In addition, Riera-Crichton

\footnotetext{
${ }^{1}$ We also briefly study a panel of 20 developed economies to initially compare the size of fiscal multipliers and the reaction of monetary policy. For analytical convenience, the whole set of 41 countries is similar to the one studied by Ilzetzki et al (2013).
} 
et al (2015) discover that fiscal multipliers are larger during recessions in OECD countries, especially when they coincide with countercyclical fiscal policies.

The literature on the interaction between monetary and fiscal policies is mostly based on general equilibrium models. Davig and Leeper (2011) use a DSGE model to study monetaryfiscal policy interaction and find that the results crucially depend on whether these polices have an active or passive role after macroeconomic shocks. On the other hand, Woodford (2011) shows, within a stylized macro model, that the size of fiscal multipliers crucially depend on the monetary policy reaction; it is in fact, much higher ate zero lower bound. Born et al (2013) also show, within an open new-Keynesian model, the importance of the monetary regime on the determination of the size of fiscal multipliers.

An alternative way to study policy interaction in the context of structural VAR, is by computing counterfactual simulations. Kuckuck and Westermann (2014) perform this kind of simulations to obtain fiscal and tax multipliers for the US which are free of any dynamic policy interaction between both policy instruments. To the best of our knowledge, our work is the first attempt to study monetary-fiscal policy interactions by computing counterfactual simulations within a panel VAR system with data for developing economies.

This paper is organized as follows. Section 2 describes the data. Section 3 reports the econometric methodology. Section 4 shows the empirical results for alternative macroeconomic features of the countries under study. Finally, Section 5 makes some concluding statements.

\section{Data Description}

We use data for 21 developing economies: Argentina, Botswana, Brazil, Bulgaria, Chile, Colombia, Croatia, Ecuador, El Salvador, Hungary, Latvia, Lithuania, Malaysia, Mexico, Peru, Poland, Romania, Slovak Republic, South Africa, Thailand and Turkey. We choose this set of countries due to their availability of fiscal and monetary macro data ${ }^{2}$. We follow the World Bank's classification to define the "developing" category.

For each country we retrieve data to compute the following quarterly indicators: i) real gross domestic product, ii) real government consumption, iii) real effective exchange rate, iv) real monetary policy rate, and v) real Money Balances (M2). Series for all countries span the first quarter of 2000 until the first quarter of 2015. These data have good quality and fairly easy access since they are retrieved from International Financial Statistics (IFS), OECD, Eurostat, national statistical agencies and central banks.

\footnotetext{
${ }^{2}$ Our dataset also includes the following 20 developed economies: Australia, Belgium, Canada, Denmark, Finland, France, Germany, Greece, Iceland, Ireland, Israel, Italy, Netherlands, Norway, Portugal, Slovenia, Spain, Sweden, United Kingdom, and United States of America.
} 
We compute annual growth rates for each variable in each country to correct for nonstationarity and seasonality of the data. That is, we compute the difference between the log level of each variable at $t$ and $t-4$. In the case of the real interest rate we do not use logs but only differences between percentage points. In the Appendix, we present results of panel unit root tests for all five panels of variables, after differencing (Tables 2 and 3).

\section{Econometric Methodology}

The main challenge when computing fiscal multipliers is the proper identification of fiscal shocks. We use the Structural Vector Auto Regression (SVAR) approach first employed by Blanchard and Perotti (2002). In this approach, a key identification assumption is that policy decisions about government consumption require at least a quarter to respond to innovations in other macroeconomic variables, including GDP.

Since our focus is the interaction between monetary and fiscal policies, we need to simultaneously identify both shocks. To identify monetary policy shocks, we use the SVAR approach following Kim (2003) and Anzuini et al (2013). Their strategy consists of controlling for money demand and including short-run restrictions so that money demand contemporaneously react to interest rate and output shocks. Monetary policy rates instead, take longer to react to output innovations.

We use the Cholesky decomposition to perform this identification. The variables are included in the following ordering: Government consumption, monetary policy rate, GDP, real money balances (M2) and real exchange rate. Such ordering implies that the real exchange rate and M2 are the variables that react contemporaneously to shocks on the remaining variables of the system. In addition, policy variables are those with the most lagged reaction to macroeconomic shocks ${ }^{3}$.

Alternative identification methods for fiscal shocks use natural experiments such as military build-ups (Ramey and Shapiro, 1998) or large international loan disbursements (Kraay, 2012 and 2014). These data are not available for all the countries in our sample. In addition, strict assumptions about the unpredictability by the private sector of these government operations are required and might not hold in every economy.

We estimate the following Panel VAR system:

$$
Y_{i t}=Y_{i t-1} A_{1}+Y_{i t-2} A_{2}+\cdots+Y_{i t-p} A_{p} u_{i t}+u_{i}+e_{i t} \quad i=1, \cdots, N \quad t=1, \cdots, T
$$

\footnotetext{
${ }^{3}$ Mountford and Uhlig (2009) propose an alternative identification approach for fiscal policy, monetary policy and business-cycle shocks within the same VAR system. This approach uses sign and orthogonality restrictions for the identification of shocks. However, their results for the US are in line with other estimations.
} 
This is a homogeneous panel VAR of order $p$, with $k$ dependent variables and with panelspecific fixed effects. The vector $Y_{i t}$ contains the dependent variables for country $i$ at quarter $t$. Country-specific fixed effects are shown in the $\mathrm{k}$-vector $u_{i}$. Idiosyncratic errors for each country and quarter, are contained in the k-vector $e_{i t}$. We want to estimate the $(k \times k)$ matrices of coefficients $A_{1}, A_{2}, \cdots A_{p}$. The errors are assumed to be zero-mean and serially uncorrelated.

We follow the estimation and lag selection procedures suggested by Abrigo and Love (2016). The optimal lag order $(\phi)$ is selected using the consistent model selection criteria (MMSC) proposed by Andrews and $\mathrm{Lu}$ (2001) which are based on the test for over-identifying restrictions (J statistic) devised by Hansen (1982). The estimation is performed using a GMM approach to Equation (1). This method employs instruments to guarantee the consistency of estimators, especially in fixed $\mathrm{T}$ and large $\mathrm{N}$ settings. Instead of a first difference transformation, this method uses forward orthogonal transformation which minimizes data loss when instrumenting. Finally, the whole system is estimated as a system of equations since it allows efficiency gains and makes cross-equation testing possible.

We perform counterfactual simulations of the effects of government consumption shocks by shutting down the estimated monetary policy reaction and allowing all the remaining feedbacks of the system to operate. These exercises allow obtaining impulse-response functions which are free of the monetary policy reaction implied by the data. Therefore, the difference between unrestricted and counterfactual fiscal multipliers can be used to compute the approximate gains (or losses in some cases) from a coordinated monetary-fiscal policy in terms of GDP.

We compute fiscal multipliers from 0 to 20 quarters using the following standard formula:

$$
f m(T)=\frac{\sum_{t=0}^{T}(1+r)^{-t} \Delta y_{t}}{\sum_{t=0}^{T}(1+r)^{-t} \Delta g_{t}}
$$

In this equation, the cumulative fiscal multiplier in period $T$ is defined as the present value of the implied changes in GDP divided by the present value of changes in government consumption. Both $\Delta y_{t}$ and $\Delta g_{t}$ are extracted from their respective impulse-response functions. The discount interest rate $(r)$ corresponds to the average real policy rate across all countries and periods of analysis. Impact, medium-run and long-run multipliers correspond to $\mathrm{T}=0$, $\mathrm{T}=10$ and $T=20$, respectively, in Equation 2. This definition of fiscal multipliers is standard in the literature, except for the use of a real interest rate to discount future floes of GDP and government consumption (Chinn, 2013). However, for low values of this interest rate, the effect of discounting on the size of the multiplier is very small.

\section{Empirical Results}

In this section, we initially present results on the implications of a government consumption shock in developed and developing economies. Then, we describe the results during alternative exchange rate regimes, business-cycle phases and monetary policy-stances in developing 
economies. In every case, we show impulse-response functions for all variables of the system and then the implied cumulative fiscal multiplier. Every figure compares predicted and counterfactual multipliers. Using the procedure by Andrews and Lu (2001), optimal lag orders for developed and developing economies are $p=1$ and $p=2$, respectively. See tables 4 and 5 in the Appendix.

\subsection{Developed versus Developing Economies}

Figure 1 shows impulse responses of all variables in the system to a one standard-deviation government consumption shock in high-income economies. These graphs describe both the unrestricted and counterfactual responses during 20 quarters after the initial shock. The counterfactual responses exclude the monetary policy reaction implied by the data.

It is clear from Figure 1 that the increase of government consumption has a consistent positive effect on GDP lasting more than 20 quarters. Notice most of the monetary policy reaction is expansionary since interest rates are reduced during all 20 quarters, except for the impact effect. However, the monetary policy effect on the transmission of the fiscal shock on GDP is very small since the counterfactual response is very similar to the unrestricted one.

Figure 2 presents the cumulative fiscal multiplier implied by the GDP response depicted in Figure 1. The impact multiplier (immediately after the shock) is 0.83 . It starts gradually increasing until reaching 2.8 in the medium-run $\left(10^{\text {th }}\right.$ quarter $)$ and 3.05 in the long run $\left(20^{\text {th }}\right.$ quarter). The counterfactual multiplier is slightly lower (3.04 in the long-run). Therefore, there is no role for further fiscal-monetary policy coordination in developed economies.

Figure 3 shows impulse responses for developing economies. The response of GDP is initially positive during the first 6 quarters after the shock. Then it becomes negative but close to zero during the remaining quarters. Notice that the monetary policy reaction is cyclical, initially expansionary and then, 4 to 9 quarters after the shock, it becomes contractive. At the end, it becomes again expansionary. The counterfactual GDP response is slightly below the unrestricted response.

The impact multiplier is 0.18 and its maximum is 0.44 which occurs 5 quarters after the shock, see Figure 4. Afterwards, it starts decreasing gradually until reaching 0.35 in the medium run and 0.28 in the long-run. The counterfactual multiplier is slightly lower which shows that further fiscal-monetary policy coordination is no needed for the average developing economy. In the following figures we further explore these results in developing economies by exploring alternative episodes of exchange-rate regimes, business-cycle phases and monetary policy stances. 
Figure 1. Impulse-response functions in developed economies.

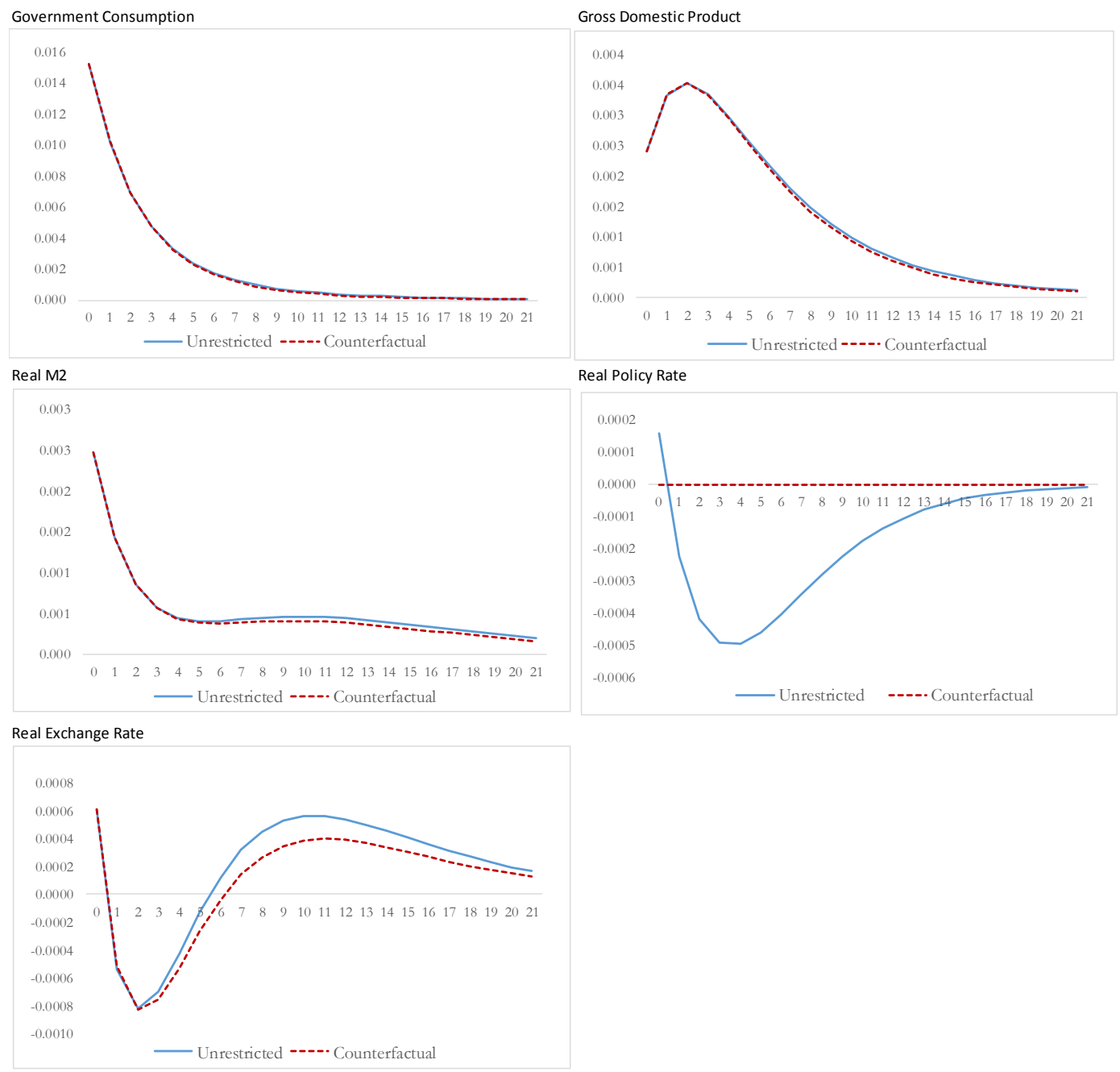

Source: Authors' computations

Figure 2. Cumulative fiscal multiplier in developed economies.

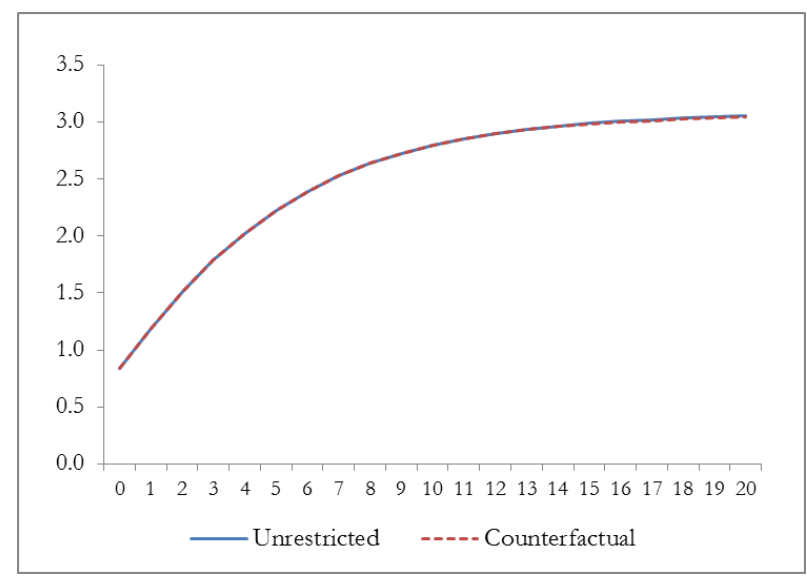


Source: Authors' computations

Figure 3. Impulse-response functions in developing economies.
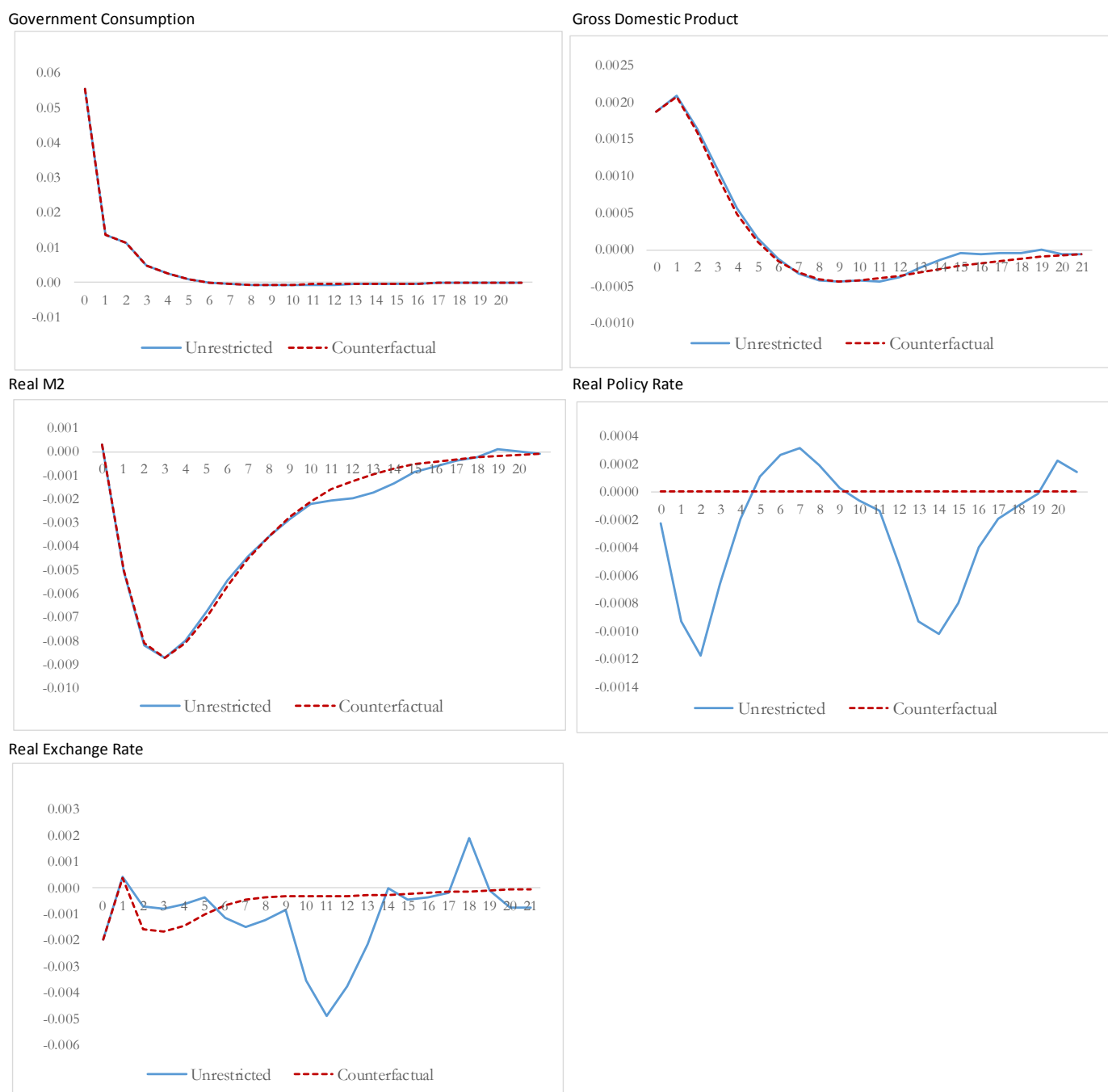

Source: Authors' computations

Figure 4. Cumulative fiscal multiplier in developing economies.

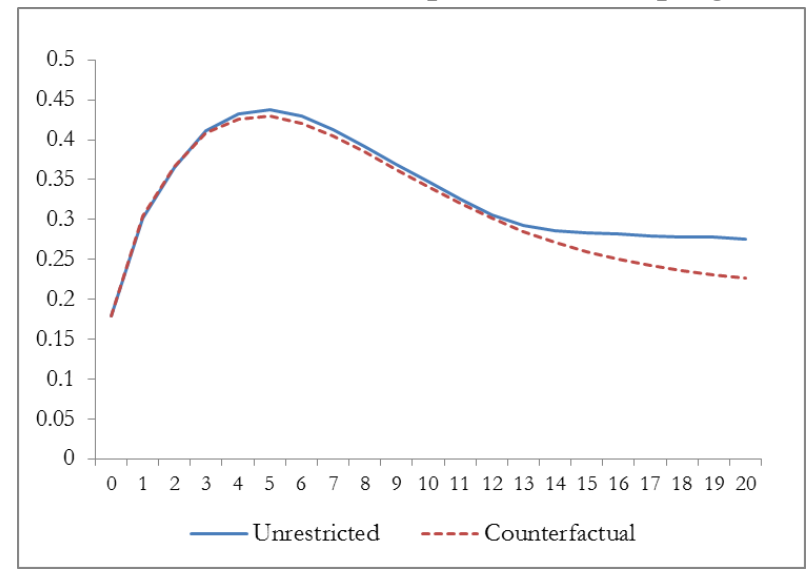

Source: Authors' computations 


\subsection{Exchange-Rate Regimes in Developing Economies:}

We study whether the low fiscal multiplier in developing economies can be explained by the exchange rate regime. Following Ilzetzki et al (2013), the dataset is divided into episodes of flexible and fixed regimes using the classification by Reinhart and Rogoff (2004) updated with information from the International Monetary Fund (IMF) until 2015. Fixed-rates episodes are defined by legal tenders, hard pegs, crawling pegs, and bands. All other cases are classified as flexible regimes. Most countries alternate between fixed and flexible exchange rate regimes.

Figure 5 shows the impulse-responses to a government consumption shock in developing economies with fixed exchange rate regime. Notice that the response of GDP is positive during 6 quarters after the shock and then becomes essentially zero. Monetary policy becomes consistently expansionary during all 20 quarters after the shock.. The fiscal multiplier (Figure 6) is initially 0.34 on impact, and reaches a maximum of $0.53,5$ quarters later. The medium-run and long-run multipliers are 0.47 and 0.5 , respectively. The counterfactual simulation implies that there is no role for further fiscal-monetary policy coordination. These results are consistent with the predictions of the Mundell-Fleming model for fixed exchange regimes.

During flexible regimes (Figure 7), the unrestricted GDP response is positive during 6 quarters and then it becomes negative but close to zero. This reaction is partly related to the increase in the monetary policy rate observed in the same figure since the counterfactual GDP response is clearly higher. Figure 8 shows that the implied fiscal multiplier is essentially zero on impact and then it gradually grows to reach a maximum of $0.34,4$ quarters after the shock. Medium and long-run unrestricted multipliers are 0.21 and 0.08 , respectively. The counterfactual simulation shows that in this case there is a key role for fiscal-monetary policy coordination since counterfactual multipliers are much better: 0.49 and 0.43 , in the medium and long-run, respectively. This result is in line with the predictions of standard open-economy models in which the monetary policy reaction is the reason for low fiscal multipliers in economies with flexible regimes; see for example, McCallum (1996). However, the size gap between developed and developing economies is not fully explained by this lack of coordination. 
Figure 5. Impulse-response functions in developing economies during fixed exchange rates

Government Consumption
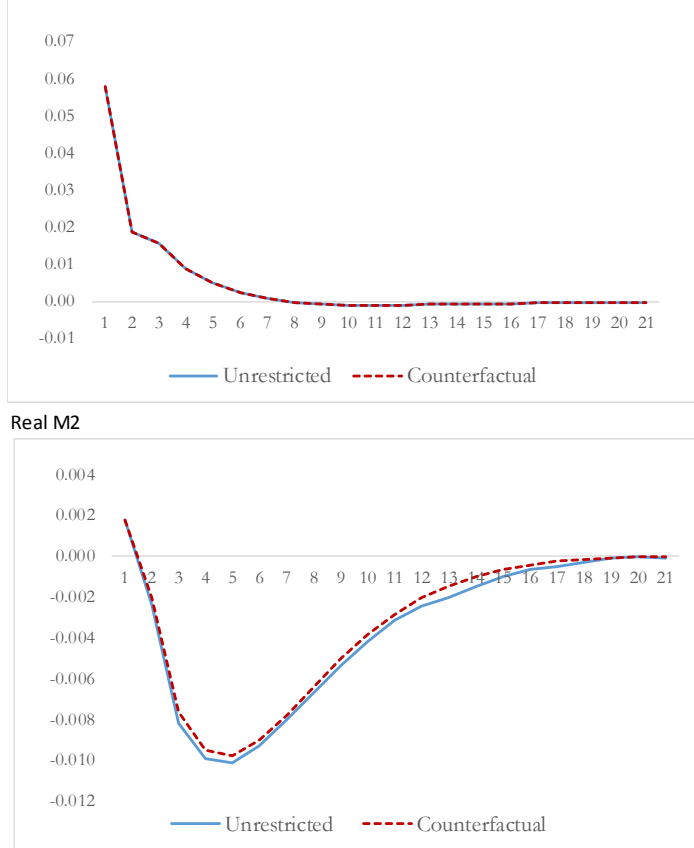

Real Exchange Rate

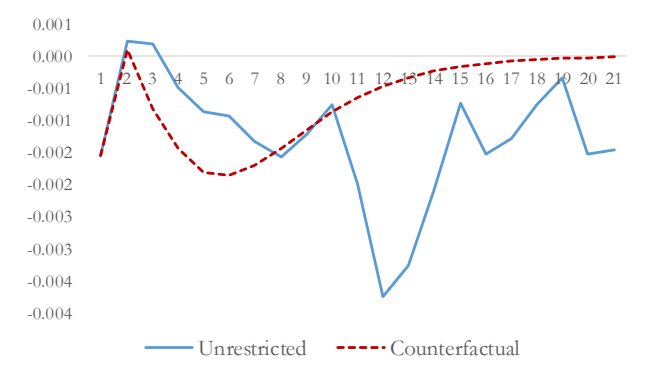

Source: Authors' computations

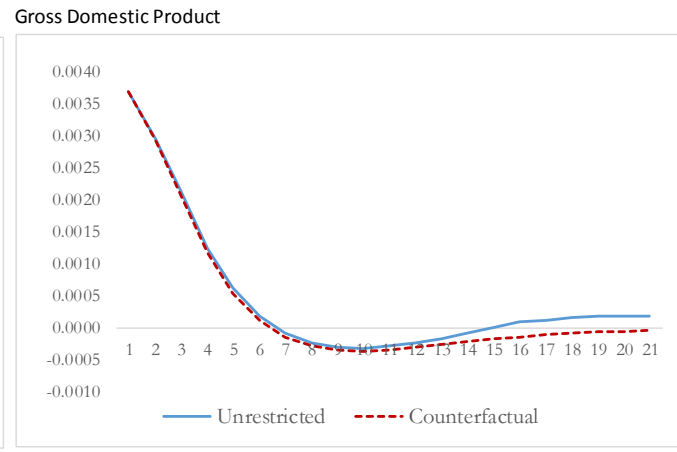

Real Policy Rate

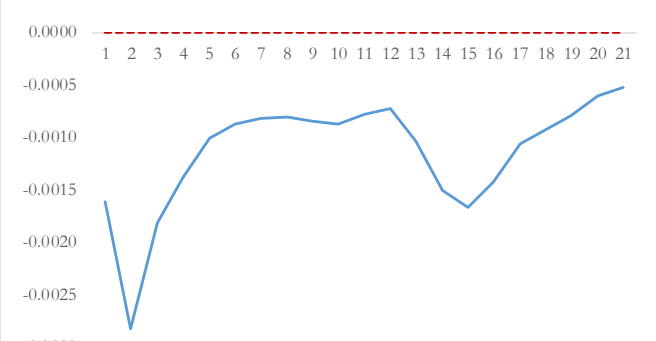

$-0.0030$

- Unrestricted ----- Counterfactual

Figure 6. Cumulative fiscal multiplier in developing economies with fixed exchange rate.

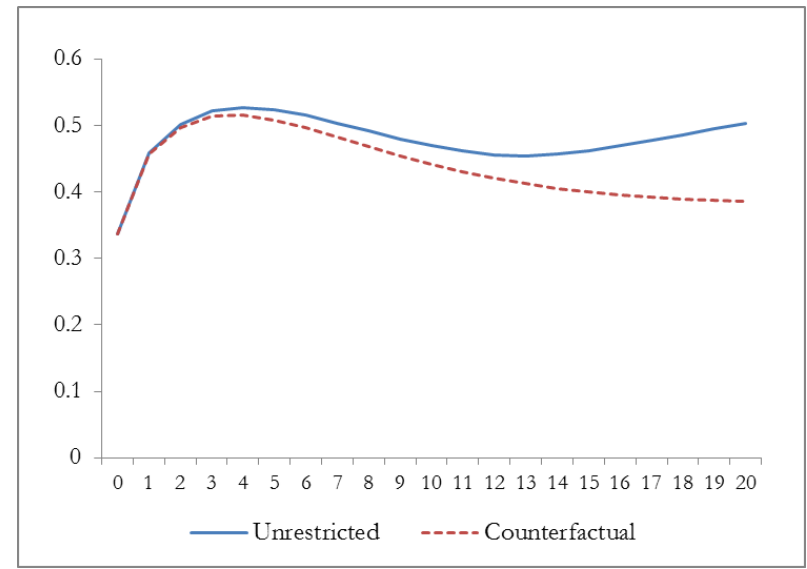

Source: Authors' computations 
Figure 7. Impulse-response functions in developing economies during flexible exchange rates

Government Consumption
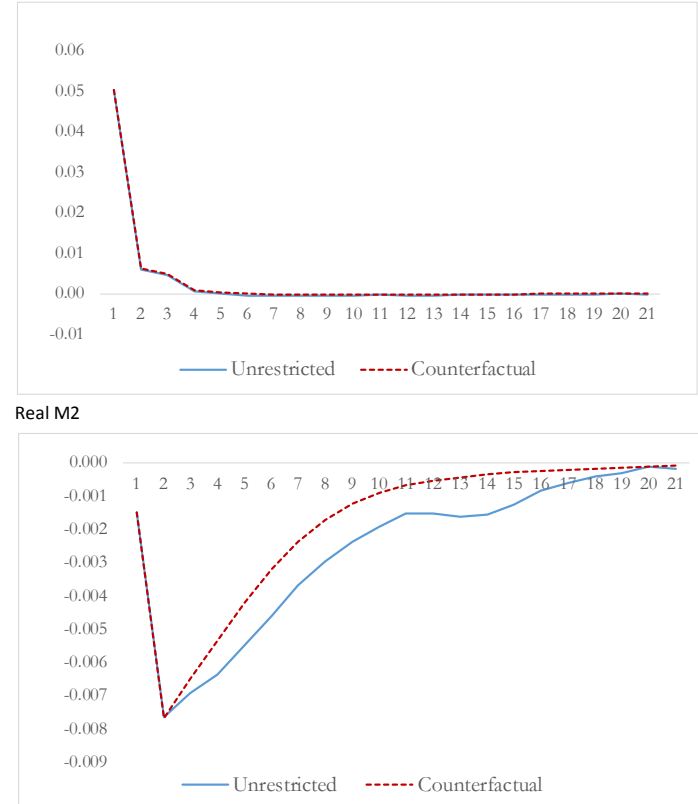

Real Exchange Rate

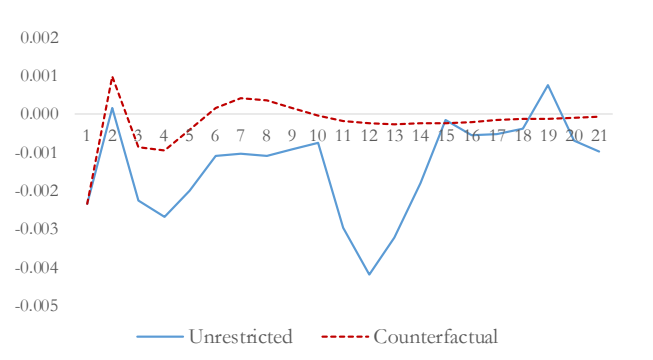

Source: Authors' computations
Gross Domestic Product

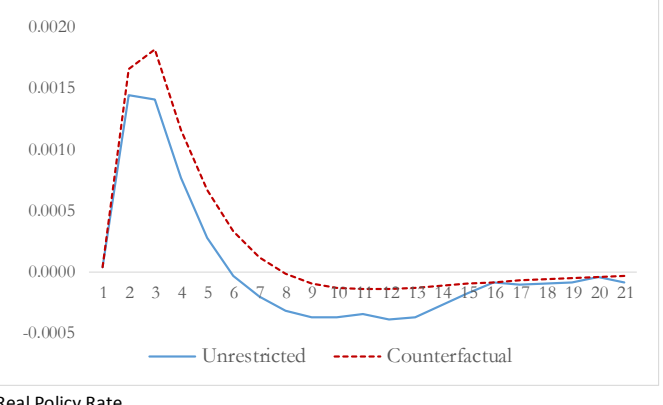

Real Policy Rate

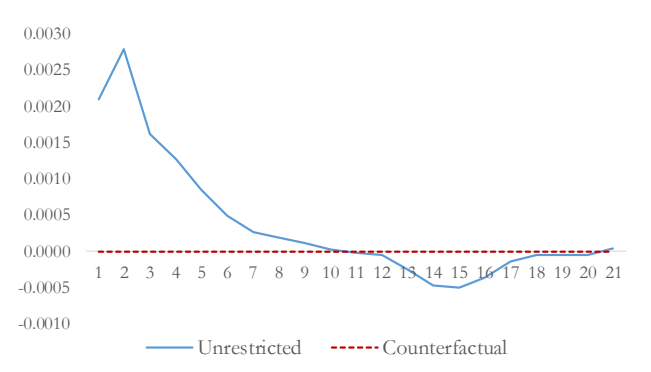

Figure 8. Cumulative fiscal multiplier in developing economies with flexible exchange rates.

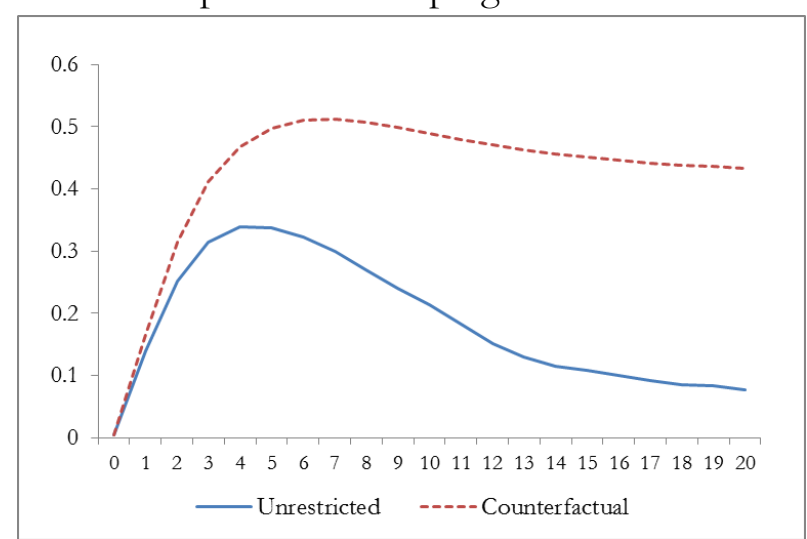

Source: Authors' computations 


\subsection{Business-Cycle Phases in Developing Economies}

In this section we divide the set of developing economies into two alternative stances of economic activity: booms and recessions. We would like to explore whether the low fiscal multipliers in these economies are related to the business-cycle phase. This exercise follows the approach by Auerbach and Gorodnichenko (2012), Riera-Crichton et al (2015), among other works.

We apply a quarterly Hodrick-Prescott filter to real GDP data, country by country, to estimate their trend. We define as recessions (booms) those periods when observed GDP is below (above) such trend ${ }^{4}$. Notice that all countries have several alternative episodes of booms and recessions and our econometric methodology allows computing fiscal multipliers on these subsets of data. Since the average duration of these phases is around 8 quarters in developing economies, we are presenting impulse responses only up to 10 quarters after the shock.

Figure 9 shows impulse responses in the case of GDP booms. The response of GDP is positive after the eighth quarter after the shock. At the same time, we observe an increase of the monetary policy rate after the first quarter. The implied cumulative fiscal multiplier (Figure $10)$ is positive on impact (0.22) and reaches a maximum of 0.51 in the sixth quarter. Then it starts decreasing gradually until reaching a medium-run level of 0.47 . There is only a very small role for monetary-fiscal policy coordination since the counterfactual multiplier is slightly higher than the unrestricted one.

Figure 11 shows impulse-response functions in the case of economic recessions. Notice that the unrestricted GDP response is initially zero and then remains positive from quarters 1 to 5 when returns to zero. The response of monetary policy is cyclical, remaining positive between quarters 2 and 6. In line with these results, the implied fiscal multiplier (Figure 12) is initially close to zero but then it starts increasing until reaching 0.26 in the fifth quarter and a very similar level in the medium-run (tenth quarter). There is a small role for fiscal-monetary policy coordination since the multiplier is slightly higher in the countercyclical simulation.

The result that cumulative multipliers are higher during booms than during recessions does not accord with recent literature, for example, Auerbach and Gorodnichenko (2012). Most of these recent works use data for developed economies (OECD countries). Further work on the reasons for this reversal in the case of developing economies, is needed. A first hypothesis would be that developed economies have more fiscal space during recessions that developing ones.

\footnotetext{
${ }^{4}$ In practice, since the optimal lag order is 2, we only consider boom or recession episodes of at least 3 quarters.
} 
Figure 9. Impulse-response functions in developing economies during economic booms
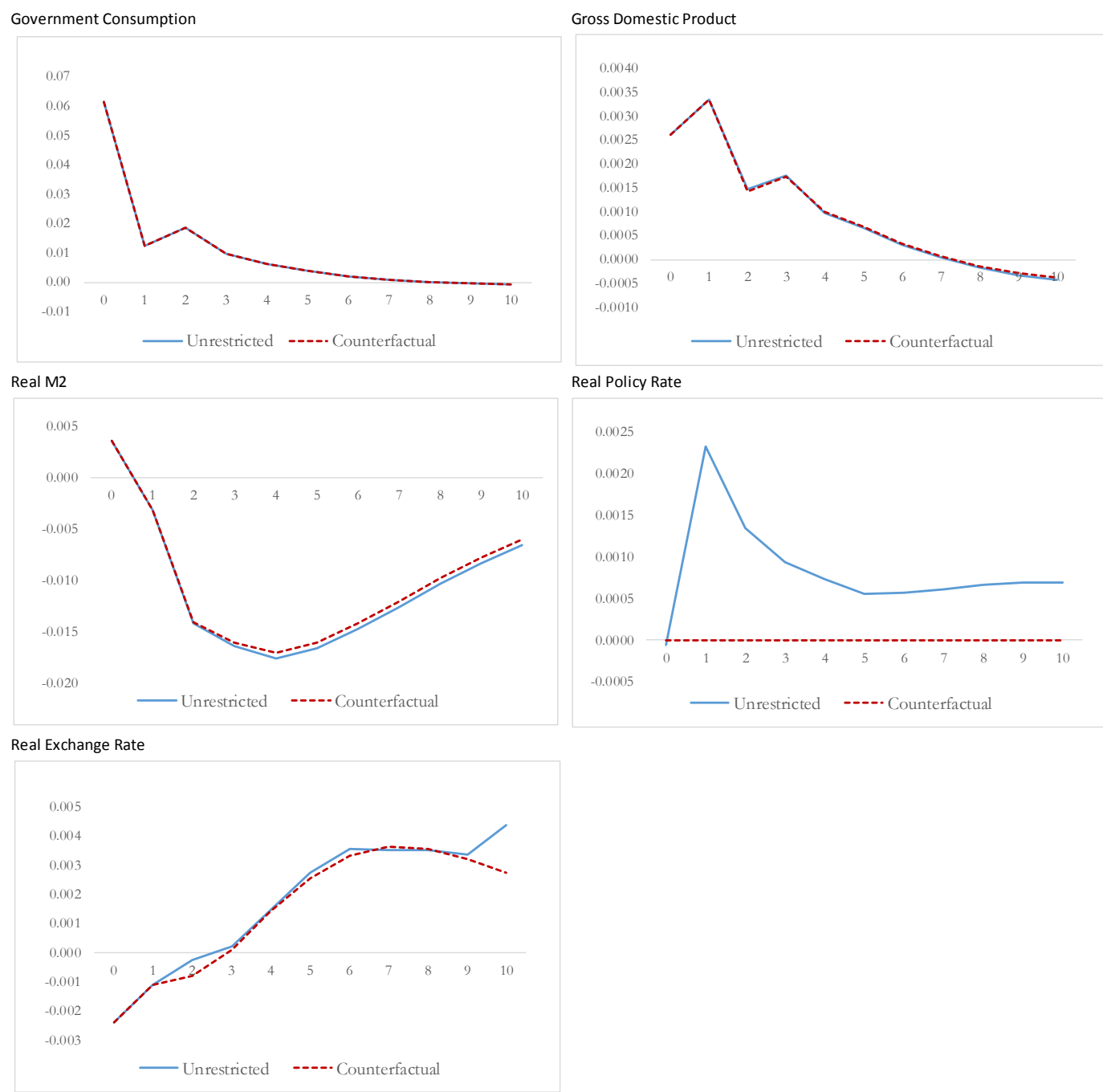

Source: Authors' computations

Figure 10. Cumulative fiscal multiplier in developing economies during economic booms.

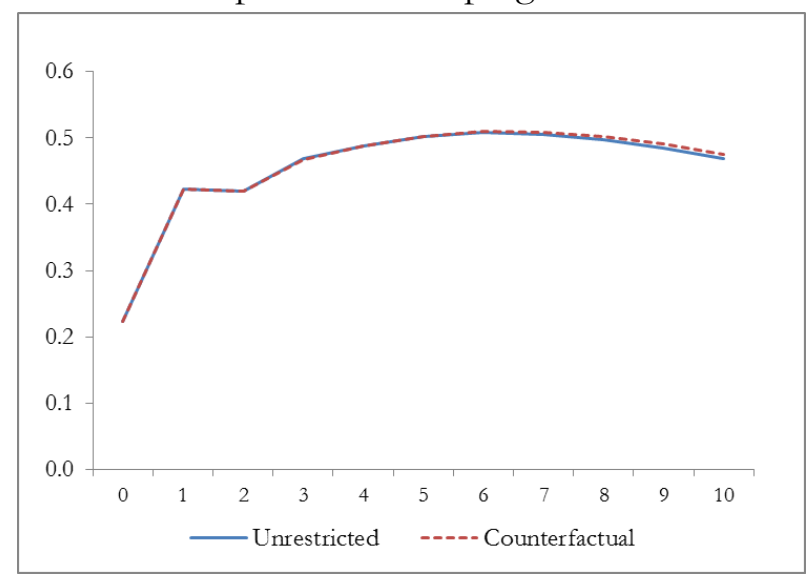

Source: Authors' computations 
Figure 11. Impulse-response functions in developing economies during economic recessions

Government Consumption

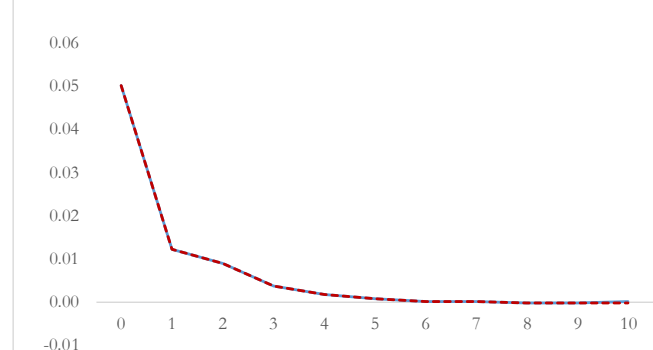

Real M2 $\quad$ Unrestricted $---\cdot$.- Counterfactual

$\begin{array}{rrrrrrrrrrrr}0.000 & 0 & 1 & 2 & 3 & 4 & 5 & 6 & 7 & 8 & 9 & 10\end{array}$

$-0.002$

$-0.003$

$-0.004$

$-0.006$

$-0.007$

$-0.008$

$-0.009$

$-0.010$

Real Exchange Rate

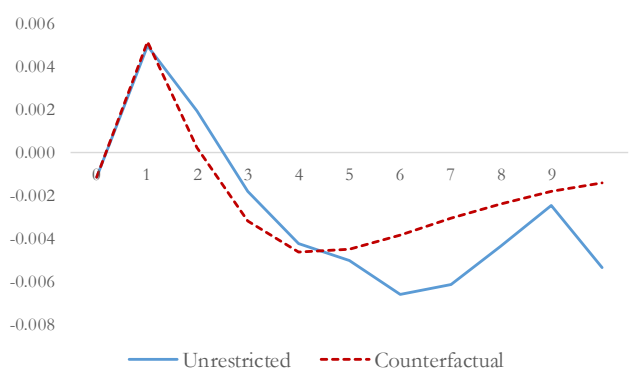

Source: Authors' computations
Gross Domestic Product

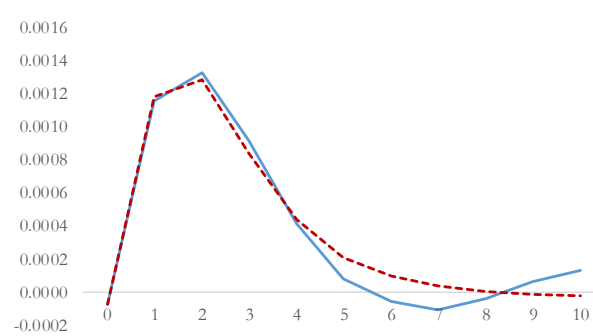

Real Policy Rate

0.0025

0.0020

0.0015

0.0010

0.0005

0.0000

$-0.0005$

$-0.0010$

$-0.0015$

$-0.002$

- Unrestricted ----. Counterfactual

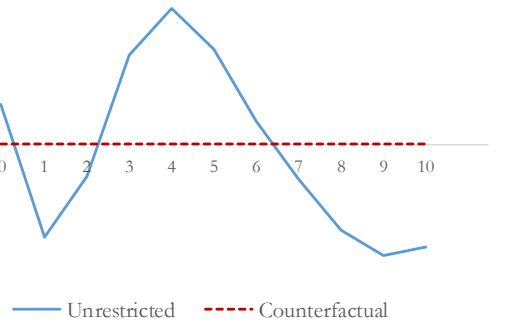

- Unrestricted $\quad---\cdot$.-Counterfactual

Figure 12. Cumulative fiscal multiplier in developing economies during economic recessions.

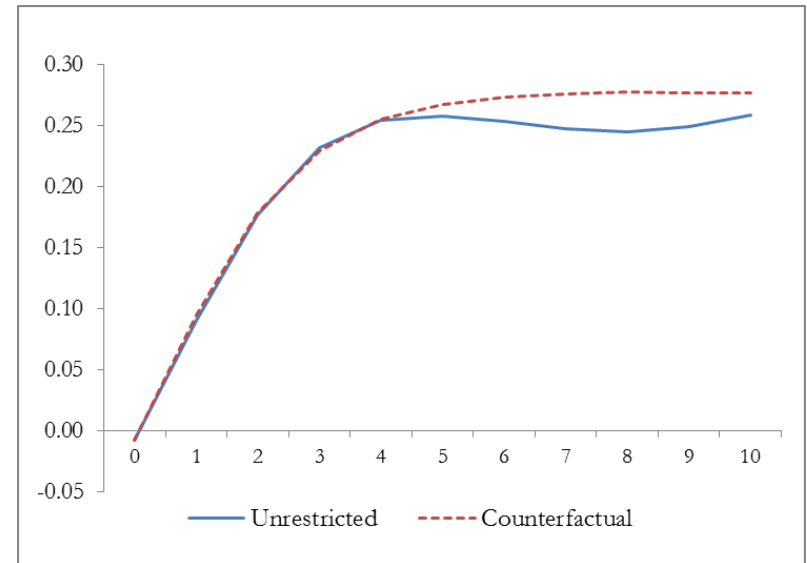

Source: Authors' computations 


\subsection{Monetary Policy Stances in Developing Economies}

An additional exercise is studying whether the transmission of fiscal policy is affected by the current stance of monetary policy. Woodford (2011), for example, shows a model in which fiscal policy is more effective when monetary policy approaches the zero lower bound. For this exercise, first we compute Hodrick-Prescott trends on the real policy rate, country by country. This trend would be a proxy of the natural interest rate. We define episodes of monetary contraction (expansion) as those quarters when the real policy rate is above (below) its trend ${ }^{5}$. Since these monetary policy stances have similar durations to business cycles, we present impulse responses and cumulative multipliers only up to 10 quarters after the shock.

Figure 13 shows the impulse responses in the case of episodes of monetary expansions. The GDP response is positive during all 10 quarters after the shock. In addition, the policy rate response is negative and the real exchange rate tends to depreciate. Notice that both reactions are expected to improve the transmission of the fiscal policy shock. The implied cumulative multiplier (Figure 14) is small on impact (0.22) it then starts to increase gradually and reaches a medium-run level of 1.37 which is outstanding given the average multiplier estimated for developing economies (Figure 4). It seems that, similarly to Woodford (2011), the relatively low real interest rates bring about good financial conditions to improve the fiscal stimulus.

Figure 15 shows impulse response functions in developing economies when the real interest rate is above its trend, that is, during monetary contractions. In this case, starting in the second quarter after the shock, the GDP reaction is negative. Meanwhile, the implied monetary policy reaction is cyclical and there is some real exchange rate depreciation between quarters 1 and 6 . This GDP reaction leads to an insignificant impact multiplier (Figure 16) of 0.04 that starts going downward until reaching -0.78 in the medium run. The counterfactual multiplier is very similar. This negative multiplier is likely the result of increased sovereign risk in these economies after the fiscal shock, with tight financial conditions due to the contractive monetary policy.

These results have important policy implications for developing economies; namely, fiscal stimulus programs are especially effective if implemented during monetary expansions. This result is new in the literature for developing economies and it is somewhat related to the result by Woodford (2011) on the effectiveness of fiscal expansions at the zero lower bound. This finding also shows the possibility of further fiscal-monetary policy coordination to improve the effects of fiscal stimulus programs.

\footnotetext{
${ }^{5}$ Similarly to business-cycle phases, in practice we only consider monetary-policy stances of at least 3 quarters long since the Panel VAR includes 2 lags for all variables.
} 
Figure 13. Impulse-response functions in developing economies during monetary expansions

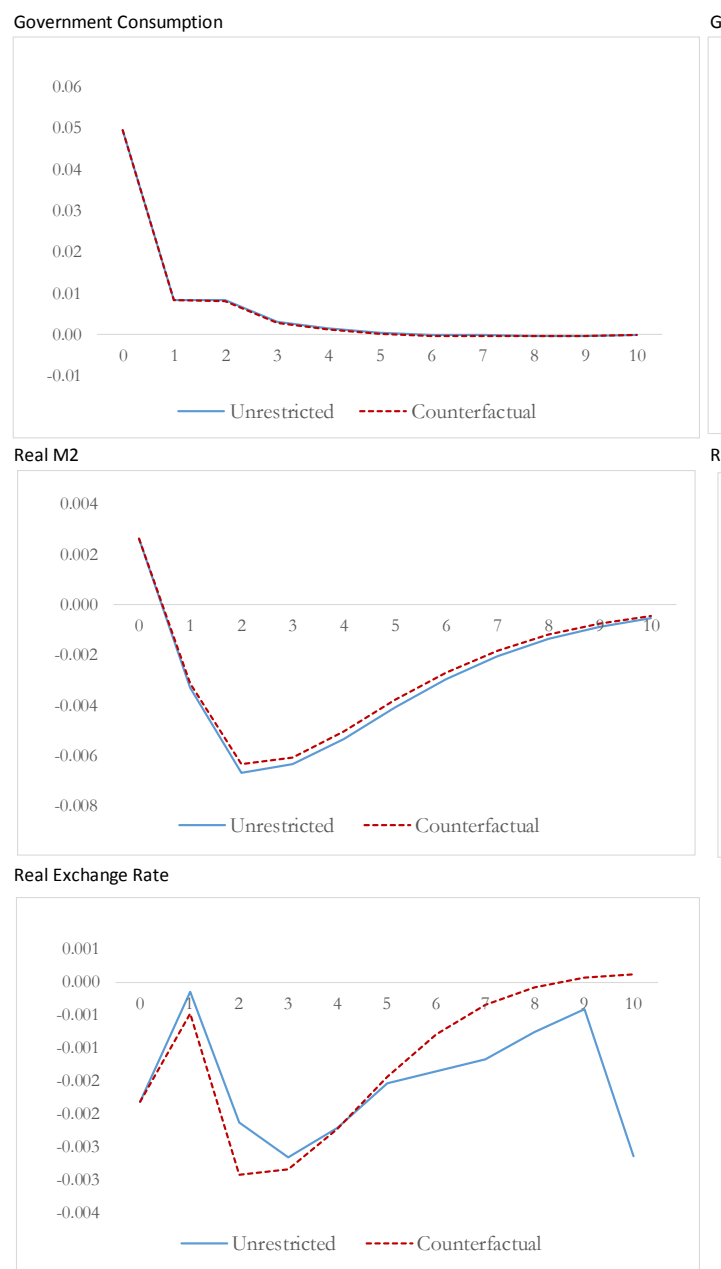

Gross Domestic Product

Source: Authors' computations

Figure 14. Cumulative fiscal multiplier in developing economies during monetary expansions.

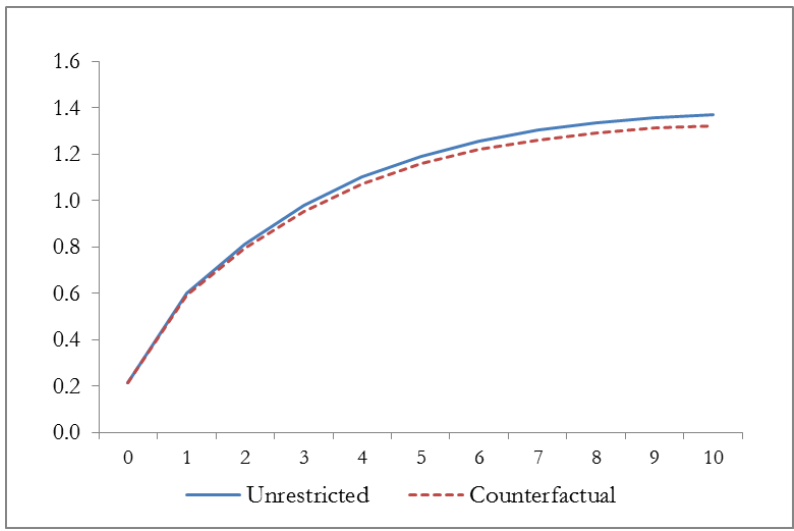

Source: Authors' computations 
Figure 15. Impulse-response functions in developing economies during monetary contractions

Government Consumption

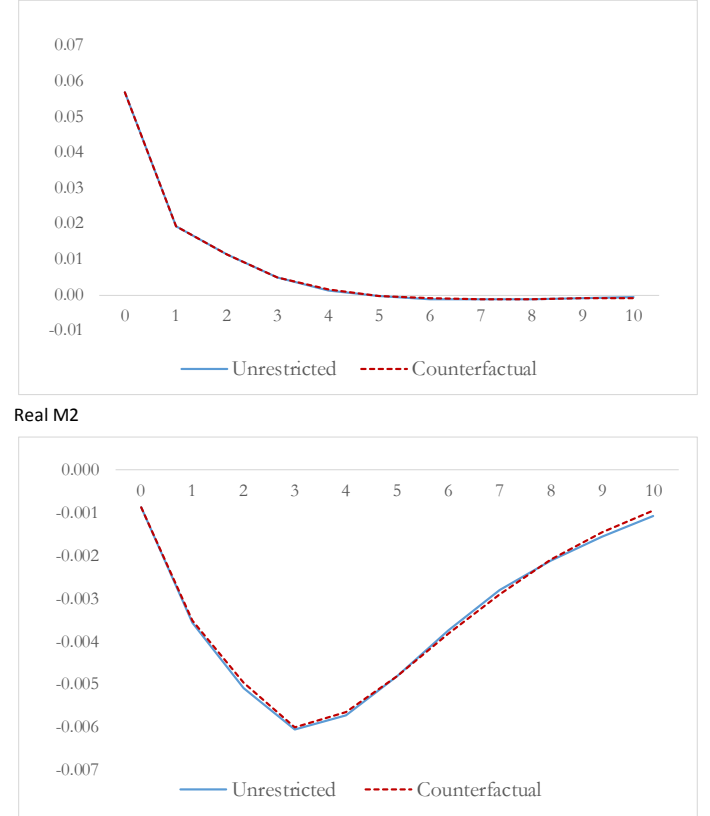

Real Exchange Rate

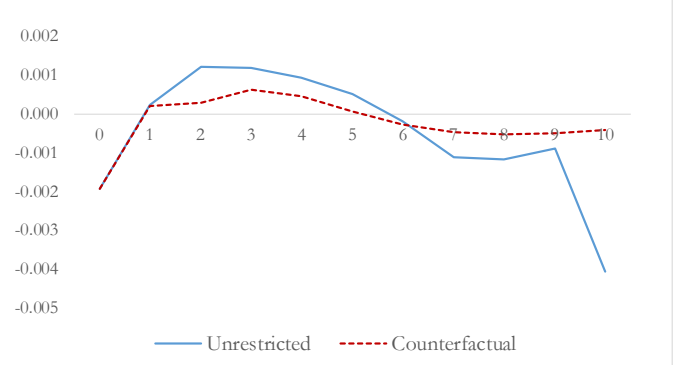

Source: Authors' computations
Gross Domestic Product

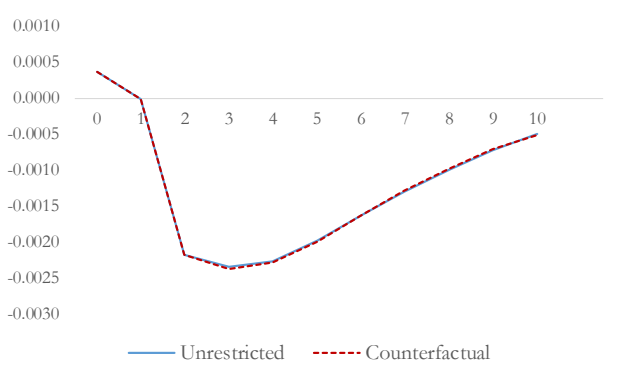

Real Policy Rate

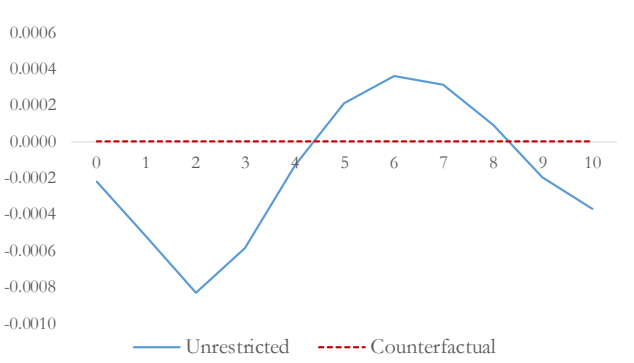

Figure 16. Cumulative fiscal multiplier in developing economies during monetary contractions.

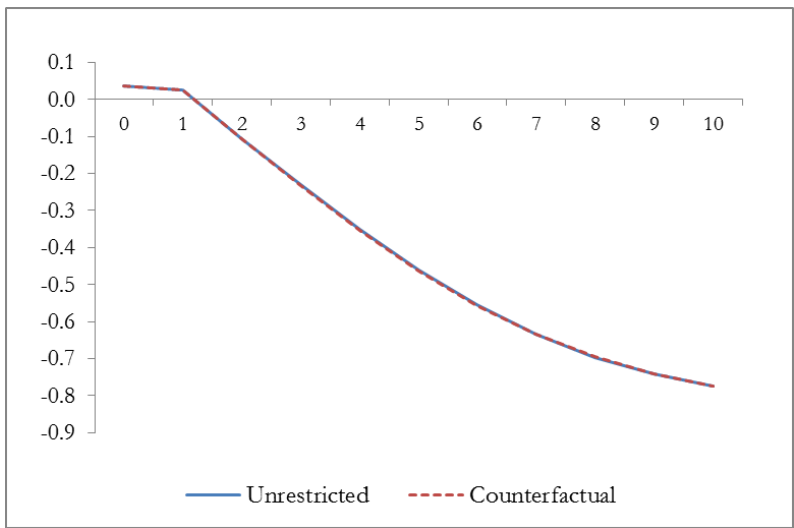

Source: Authors' computations 


\subsection{Statistical Significance of Fiscal Multipliers}

We perform statistical significance tests on fiscal multipliers by computing confidence bands on the cumulative GDP response. This estimation is based on Abrigo and Love (2016) and uses 10000 Montecarlo draws from the estimated panel VAR using Gaussian approximation. In Table 1 we present selected multipliers for panel subset and report if they are significant with a confidence degree of at least $90 \%$.

The results discussed previously in section 4 remain similar once the statistical significance results are taken into account. First, while multipliers for developed economies are high and significant, multipliers for developing economies are low and only significant on impact. In developing economies, multipliers are significant on impact for fixed exchange rate regimes, boom episodes and monetary expansions. On the medium-term, multipliers are only significant in developing economies if the shock takes place during a monetary expansion. The latter result is new in the literature and has interesting policy implications.

Table 1 - Summary of Unrestricted Fiscal Multipliers for Alternative Horizons

\begin{tabular}{|l|c|c|c|c|c|}
\hline Panel Subset & Impact & $5^{\text {th }}$ quarter & $\begin{array}{l}\text { Medium Term } \\
\left(10^{\text {th }} \text { quarter }\right)\end{array}$ & $\begin{array}{l}\text { Long Term } \\
\left(20^{\text {th }} \text { quarter }\right)\end{array}$ & \# of observations \\
\hline Developed & $0.83^{* *}$ & $2.22^{* *}$ & $2.80^{* *}$ & $3.05^{* *}$ & 1180 \\
\hline Developing & $0.18^{* *}$ & 0.44 & 0.35 & 0.28 & 1218 \\
\hline Developing - Fixed Reg. & $0.34^{* *}$ & 0.52 & 0.47 & 0.50 & 643 \\
\hline Developing - Flex. Reg. & 0.00 & 0.34 & 0.21 & 0.08 & 605 \\
\hline Developing - Boom & $0.22^{* *}$ & 0.50 & 0.47 & NA & 328 \\
\hline Developing - Recession & -0.01 & 0.26 & 0.26 & NA & 445 \\
\hline Developing - Mon. Exp. & $0.22^{* *}$ & $1.19^{* *}$ & $1.37^{* *}$ & NA & 369 \\
\hline Developing - Mon. Con. & 0.04 & -0.46 & -0.78 & NA & 371 \\
\hline
\end{tabular}

** Significant with a confidence degree of at least $90 \%$; NA: Not available

Source: Authors' computations 


\section{Concluding Statements}

In this work, we study the size of fiscal multipliers and the transmission channels of government consumption shocks, using panel data for 21 developing economies. The goal is to better understand the reasons for the existence of low fiscal multipliers in these economies. We also explore the role of fiscal-monetary policy coordination by computing counterfactual simulations in which the implied monetary policy reaction to the shock is shut down. Furthermore, we estimate fiscal multipliers in subsets of the data for alternative degrees of development, exchange-rate regimes, business-cycle phases and monetary policy stances.

We find that relative to developed economies, fiscal multipliers in developing economies are positive but very low. Among developing ones, we find higher multipliers in fixed exchange rate regimes, during economic booms and during monetary expansions. Fiscal multipliers are especially big during episodes of monetary expansion since they reach levels above one in the medium-run.

Using counterfactual simulations, we find that by enhancing fiscal-monetary policy coordination in developing economies with flexible regime, it is possible to improve the effects of fiscal policy. Namely, fiscal multipliers would be better if the reaction of monetary policy to the fiscal shock is more gradual.

Our empirical results have important implications for developing economies. First, policy makers in these economies should be very careful before engaging in countercyclical fiscal expansions. These fiscal programs seem to work better during economic booms and more importantly, during monetary expansions. This effectiveness can be further improved if monetary authorities do not increase interest rates during the implementation of the fiscal programs.

The transmission channels of fiscal policy should be further explored using empirical estimations as well as general equilibrium macro models. Our estimations suggest that the financial stability channel might be important since government consumption shocks are mostly followed by real money demand reductions in developing economies, in contrast to developed economies. Other channels not considered in this work are: sovereign default risk and political risk. 


\section{References}

Abrigo, M. R., and I. Love, (2016). "Estimation of Panel Vector Autoregression in Stata," The Stata Journal, 16(3), pp. 778-804.

Andrews, D. W. K., and B. Lu (2001). "Consistent Model and Moment Selection Procedures for GMM Estimation with Application to Dynamic Panel Data Models," Journal of Econometrics, 101(1), pp. 123-164.

Anzuini, A., M. Lombardi, and P. Pagano, (2013). "The Impact of Monetary Policy Shocks on Commodity Prices," International Journal of Central Banking, 9(3), pp.119-144.

Auerbach, A., and Y. Gorodnichenko, (2012). "Fiscal Multipliers in Recession and Expansion," in: "Fiscal Policy after the Financial Crisis", National Bureau of Economic Research, Cambridge, MA, pages 63-98.

Blanchard, O., and R. Perotti, (2002). "An Empirical Characterization of the Dynamic Effects of Changes in Government Spending and Taxes on Output," Quarterly Journal of Economics, 117, pp. 1329-1368.

Born, B., F. Juessen, and G. Müller, (2013). "Exchange Rate Regimes and Fiscal Multipliers," Journal of Economic Dynamics and Control, 37, pp. 446-465

Chinn, M. (2013). "Fiscal Multipliers," The New Palgrave Dictionary of Economics, online edition.

Davig, T., and E. M. Leeper, (2011). "Monetary-Fiscal Policy Interactions and Fiscal Stimulus," European Economic Review, 55(2), pp. 211-227.

Favero, C., F. Giavazzi, and J. Perego, (2011). "Country Heterogeneity and the International Evidence on the Effects of Fiscal Policy," IMF Economic Review, 59(4), pp. 652-682.

Hansen, L. P., (1982).'"Large Sample Properties of Generalized Method of Moments Estimator," Econometrica, 50(4), pp. 1029-1054.

Ilzetzki, E., E. Mendoza, and C. Végh, (2013). "How big (small?) are fiscal multipliers?," Journal of Monetary Economics, 60(2), pp. 239-254.

Im, K., M. Pesaran, and Y. Shin, (2003). "Testing for Unit Roots in Heterogeneous Panels," Journal of Econometrics, 115(1): pp. 53-74

Kim, S., (2003). "Monetary policy, foreign exchange intervention, and the exchange rate in a unifying framework," Journal of International Economics, 60, pp. 355-386.

Kraay, A., (2014). "Government Spending Multipliers in Developing Countries: Evidence from Lending by Official Creditors," American Economic Journal: Macroeconomics, 6(4), pp. 170-208. 
Kraay, A., (2012). "How large is the Government Spending Multiplier? Evidence from World Bank Lending," The Quarterly Journal of Economics, 127(2), pp. 829-887.

Kuckuck, J., and F. Westermann, (2014). "On the size of fiscal multipliers: A counterfactual analysis," Economics Letters, 123(1), pp. 26-32.

McCallum, B. (1996). “International Monetary Economics”. Oxford University Press, 280 p.

Ramey, V., and M. Shapiro, (1998). "Costly Capital Reallocation and the Effects of Government Spending," In: Carnegie-Rochester Conference Series on Public Policy, 46, pp. 145-194.

Reinhart, C. and K. Rogoff, (2004). "The Modern History of Exchange Rate Arrangements: A Reinterpretation," The Quarterly Journal of Economics, 119(1), pp. 1-48.

Riera-Crichton, D., C. Vegh, and G. Vuletin, (2015). "Procyclical and countercyclical fiscal multipliers: Evidence from OECD countries," Journal of International Money and Finance, 52, pp. 15-31.

Woodford, M., (2011). "Simple Analytics of Government Expenditure Multiplier," American Economic Journal: Macroeconomics, 3(1): pp. 1-35. 


\section{Appendix with Tables}

Table 2: Panel Unit Root Tests - Developed

Test by Im, Pesaran and Shin (2003)

Null: Unit root (assumes common unit root process)

\begin{tabular}{ccc}
\hline Panel & t-bar & P-value \\
\hline Gov. Consumption & -2.8217 & 0.0000 \\
GDP & -2.7561 & 0.0000 \\
Policy rate & -3.0407 & 0.0000 \\
Real exchange rate & -2.5220 & 0.0000 \\
M2 & -2.2732 & 0.0001 \\
\hline
\end{tabular}

Source: Authors' calculations

Table 3: Panel Unit Root Tests - Developing

Test by Im, Pesaran and Shin (2003)

Null: Unit root (assumes common unit root process)

\begin{tabular}{ccc}
\hline Panel & t-bar & P-value \\
\hline Gov. Consumption & -4.0455 & 0.0000 \\
GDP & -2.4721 & 0.0000 \\
Policy rate & -3.6118 & 0.0000 \\
Real exchange rate & -2.3654 & 0.0000 \\
M2 & -2.9201 & 0.0000 \\
\hline
\end{tabular}

Source: Authors' calculations 
Table 4: Lag Selection Criteria - Developed

\begin{tabular}{|l|l|l|l|}
\hline Lags & MBIC & MAIC & MQIC \\
\hline 1 & $\mathbf{- 4 7 6 . 3 6}$ & 77.70 & $\mathbf{- 1 3 2 . 4 8}$ \\
\hline 2 & -419.96 & 54.95 & -125.21 \\
\hline 3 & -367.38 & $\mathbf{2 8 . 3 8}$ & -121.75 \\
\hline 4 & -283.14 & 33.47 & -86.63 \\
\hline
\end{tabular}

Source: Authors' calculations

Table 5: Lag Selection Criteria - Developing

\begin{tabular}{|l|l|l|l|}
\hline Lags & MBIC & MAIC & MQIC \\
\hline 1 & $\mathbf{- 5 4 9 . 0 4}$ & -10.49 & -201.26 \\
\hline 2 & -510.70 & $\mathbf{- 3 1 . 1 1}$ & $\mathbf{- 2 1 2 . 6 0}$ \\
\hline 3 & -420.22 & -20.56 & -171.81 \\
\hline 4 & -342.15 & -22.42 & -143.42 \\
\hline
\end{tabular}

Source: Authors' calculations 